\title{
DIÂMETRO DOS GRÃOS DE PÓLEN E TAMANHO DOS ESTÔMATOS EM ACESSOS DIPLÓIDES E TETRAPLÓIDES DE Hemarthria altissima (Poiret) Stapf \& Hubbard (Gramineae) ${ }^{1}$
}

\author{
POLLEN GRAIN DIAMETER AND STOMATAL SIZE IN DIPLOID AND TETRAPLOID \\ ACCESSIONS OF Hemarthria altissima (Poiret) Stapf \& Hubbard (Gramineae)
}

\author{
Solange Bosio Tedesco ${ }^{2}$ Alice Battistin ${ }^{3}$ José Francisco MontenegroValls $^{4}$
}

RESUMO

\begin{abstract}
Sete acessos da gramínea forrageira Hemarthria altissima, diplóides e tetraplóides africanos e tetraplóides brasileiros, foram analisados com fins de caracterizar, nos diferentes niveis de ploidia, os parâmetros diâmetro dos grãos de pólen e tamanho dos estômatos, com o objetivo de utilizar esses critérios para inferência de níveis de ploidia nessa espécie. As medidas foram feitas com o auxílio de um microscópio com ocular micrométrica. Os resultados demostraram que o diâmetro dos grãos de pólen podem ser utilizados para caracterizar diferentes níveis de ploidia, enquanto que o tamanho dos estômatos não é um critério seguro nessa espécie.
\end{abstract}

Palavras-chave: ploidia, gramínea forrageira, pólen, estômatos.

\section{SUMMARY}

Seven accessions of african diploid and tetraploid and brazilian tetraploid plants of Hemarthria altissima were studied to distinguish, in each ploidy level, the characters of pollen grain diameter and stomatal size. Measurements were performed with ocular micrometer microscope. Results demonstrated that pollen grain diameter can be used to characterize different ploidy levels, but the stomatal size is not a reliable criterion in this species.

Key words: ploidy, forage grass, pollen, stomata.

\section{INTRODUÇÃO}

A gramínea forrageira Hemarthria altissima, pertence à família Gramineae, tribo
Andropogoneae (BURKART, 1969). É conhecida pelo nome comum de "limpograss" (capim limpo), nome recebido nos Estados Unidos pelo fato de alguns acessos disponíveis serem originários do Vale do Rio Limpopo, na África do Sul (WILMS et al., 1970). É uma gramínea perene e tem hábito vegetativo estolonífero. No início do desenvolvimento, forma uma extensa rede de estolhos, enraizando-se através dos nós inferiores, para depois constituir uma massa vegetativa que pode atingir até $0,90 \mathrm{~m}$ de altura. Normalmente, floresce de dezembro a fevereiro, e, apesar de ser grande o número de inflorescências, a porcentagem de sementes viáveis é baixa. Atualmente, sua propagação em cultivos forrageiros é feita apenas através de mudas (POSTIGLIONI, 1983).

Sua distribuição foi relatada por SCHANK et al. (1973), com ocorrência em áreas pantanosas da África, Ásia e América do Sul. Essa espécie apresenta populações que ocorrem espontaneamente na América (ALLEM \& VALLS,1987). No Brasil, ocorre desde o Estado do Mato Grosso até a Bahia e no Rio Grande do Sul (SMITH \& WASHAUSSEN, 1981). No Rio Grande do Sul, Hemarthria altissima ocorre naturalmente e, em geral, em locais pouco perturbados pela ação humana. Foram encontradas e coletadas amostras desta gramínea em banhados nas proximidades dos municípios de Uruguaiana, Rio Grande e São Gabriel.

\footnotetext{
${ }^{1}$ Parte da dissertação de Mestrado em Zootecnia do primeiro autor - Universidade Federal de Santa Maria (UFSM), Santa Maria, RS.

${ }^{2}$ Biólogo, aluno do Doutorado em Zootecnia da Universidade Federal do Rio Grande do Sul- Porto Alegre, RS. Rua Conde de Porto

Alegre, 1368, apto. 301, 97015-110, Santa Maria, RS. Autor para correspondência.

${ }^{3}$ Naturalista, Professor Titular, UFSM.

${ }^{4}$ Engenheiro Agrônomo, PhD., Pesquisador do EMBRAPA-CENARGEN, Brasília/DF. 
Esta gramínea forrageira tem sido bastante difundida na região dos Campos Gerais no Estado do Paraná. As pesquisas que vem sendo realizadas desde 1968 na Fazenda Modelo da Fundação Instituto Agronômico do Paraná (IAPAR), em Ponta Grossa (PR), demonstraram que tem bom potencial forrageiro, além de boa qualidade de forragem. Os estudos do IAPAR foram realizados com plantas originárias da África do Sul. POSTIGLIONI (1983) obteve valores de Proteína Bruta (PB) que variaram de $8,60 \%$ a $15,19 \%$ e ressalta que o valor mínimo para percentagem de PB $(8,60 \%)$ é considerado satisfatório para as exigências de mantença de bovinos adultos. Em outros estados do Brasil, como Mato Grosso, Santa Catarina e São Paulo, também têm sido realizados estudos em $\boldsymbol{H}$. altissima, na tentativa de obter-se mais opções para alimentacão do gado. Os resultados de estudos com esta gramínea em outros países como África do Sul, Argentina, Colômbia, Venezuela e Estados Unidos (Flórida ) demonstraram que a mesma é palatável ao gado, tem bom valor nutritivo e é resistente ao pastejo e ao frio. Na Flórida, KILLINGER (1971) verificou boa performance da $\boldsymbol{H}$. altissima (PI 299995), a qual apresentou-se mais tolerante à geada que outras gramíneas comumente cultivadas, tendo um bom crescimento no início da primavera. SCHANK et al. (1973) avaliaram a digestibilidade in vitro da matéria orgânica (DIVMO) de $\boldsymbol{H}$. altissima, e, em híbridos, entre duas linhas diplóides estoloníferas. Os resultados mostraram que a DIVMO foi mais alta em uma linhagem tetraplóide (colmo grosso) africana do que qualquer uma das diplóides.

O número de gramíneas nativas do Brasil, consideradas boas forrageiras, é elevado e seu estoque genético permite sua adaptação às mais variadas condições ecológicas observáveis no território brasileiro. Este patrimônio natural vem sendo crescentemente dilapidado, muitas vezes para que, em suas áreas, sejam plantadas espécies exóticas, raramente bem testadas e, certamente, portadoras de estreita base genética (VALLS, 1986).

É necessário que as plantas, com destaque especial para as plantas forrageiras que ocorrem naturalmente no Brasil, sejam caracterizadas em todos os seus aspectos possíveis. Tendo em vista a importância da caracterização do germoplasma nativo do Brasil, neste estudo foram relacionados o diâmetro dos grãos de pólen e o tamanho dos estômatos, em acessos diplóides africanos e tetraplóides africanos e brasileiros de Hemarthria altissima, averiguando-se a possibilidade dos parâmetros citados serem utilizados com segurança na caracterização de diferentes níveis de ploidia desta gramínea.

\section{MATERIAL E MÉTODOS}

Neste trabalho foram utilizados sete acessos de Hemarthria altissima (tabela 1). As plantas foram cultivadas e mantidas em casa de vegetação na Universidade Federal de Santa Maria, RS, nos anos de 1993 e 1994. Os acessos foram cultivados em vasos de plástico, com solo Santa Maria, sem nenhum tratamento adicional. A temperatura da casa de vegetação atingiu valores médios de até $10^{\circ} \mathrm{C}$ durante o período correspondente à estação fria.

$\mathrm{Na}$ determinação do tamanho dos estômatos, utilizou-se a metodologia de raspagem de epidermes foliares, segundo técnica desenvolvida por NICOLINI (1967). Foram coletadas três lâminas foliares de cada acesso. Após a coleta, mergulharamse as lâminas foliares de cada acesso separadamente em água destilada, até a raspagem, realizada no mesmo dia, evitando dessa maneira variação na turgidez das células estomáticas.

Destacando-se parte da lâmina foliar, fezse a raspagem sob microscópio estereoscópio com lâmina de barbear comum, retirando pêlos e nervuras, facilitando o isolamento da face adaxial da epiderme, que é a área de maior ocorrência dos estômatos na espécie. Após, cada lâmina foliar foi submersa em solução de hipoclorito de sódio por 5 minutos, descolorindo-se as células clorenquimáticas e dessa forma permitindo a visualização dos estômatos bem nítidos para as medições. Na confecção das lâminas, o material raspado foi corado com safranina, e após, mediu-se 100 estômatos de cada acesso, em aumento 45X, com auxílio de um microscópio com ocular micrométrica.

Para visualização dos grãos de pólen, foi utilizada técnica de esmagamento das anteras com

Tabela 1 - Identificação e origem dos acessos de Hemarthria
altissima utilizados.

$\mathrm{GL}=$ EMBRAPA/CNPGL; $\mathrm{Mr}=\mathrm{C}$. Moraes - EMBRAPA/ CPPSUL; PI $=$ Plant Inventory $\mathrm{n}^{\circ} / \mathrm{USDA} ; \mathrm{UF}=$ University of Florida; V = J. Valls e colaboradores - EMBRAPA/CENARGEN. 
corante orceína lactopropiônica a $1 \%$ e então realizadas medições dos eixos maior e menor, considerando 200 grãos de pólen para cada acesso de forma individualizada.

\section{RESULTADOS E DISCUSSÃO}

Os resultados observados em valores médios do diâmetro dos grãos de pólen e tamanho dos estômatos estão na tabela 2.

Pode-se observar que o diâmetro médio dos grãos de pólen foi de $0,028 \mathrm{~mm}$ para os acessos diplóides, e os valores médios dos tetraplóides variaram de $0,032 \mathrm{~mm}$ a $0,036 \mathrm{~mm}$. A média dos grãos de pólen e o diâmetro médio foi menor nos acessos diplóides, com diferença de aproximadamente $20 \%$. Houve diferença estatística significativa a $5 \%$ de probabilidade dos acessos diplóides comparados com os tetraplóides (tabela 2). Não houve sobreposição de valores dos diplóides sobre os tetraplóides, sendo os diplóides bem menores que os tetraplóides (figuras 1 e 2). Assim, esses resultados indicam que o diâmetro do grão de pólen pode ser utilizado para diferenciar acessos diplóides e tetraplóides de Hemarthria altissima.

Para o tamanho dos estômatos, os resultados demonstraram que nos valores acima de $0,034 \mathrm{~mm}$ estão concentrados mais de $50 \%$ dos valores individuais de cada acesso tetraplóide, com exceção do tetraplóide Gl 460-76, o qual apresenta mais de $50 \%$ dos valores individuais concentrados em valores abaixo de $0,034 \mathrm{~mm}$. Houve sobreposição de valores individuais do tamanho dos estômatos de tetraplóides e diplóides até valores de 0,040mm;

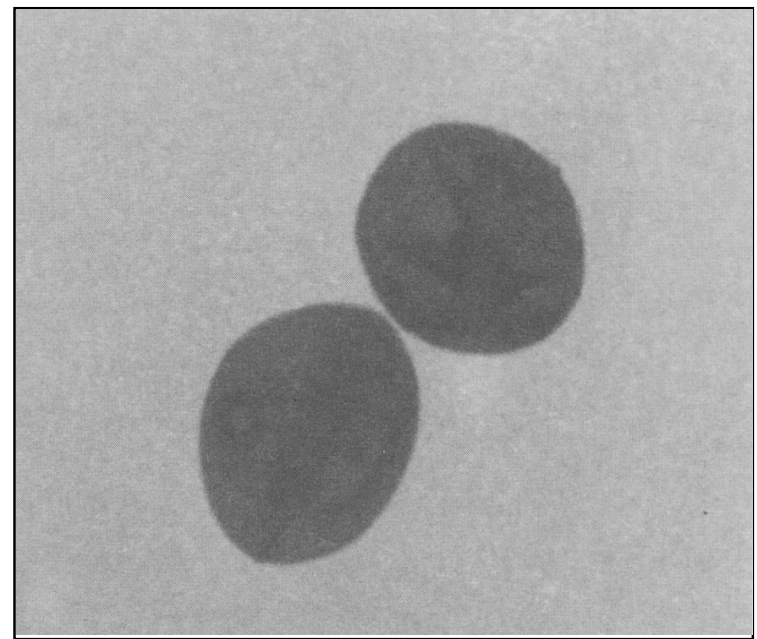

Figura 1 - Grãos de pólen Hemarthria altissima, diplóide $(2 \mathrm{n}=2 \mathrm{x}=18)$. Aumento: $1400 \mathrm{x}$.

ocorrendo alguns diplóides maiores que os tetraplóides (figuras 3 e 4). Acima de 0,040mm foram observados somente indivíduos tetraplóides, mas com frequiência reduzida. O acesso GL 460-76 não apresentou nenhum valor individual acima de $0,039 \mathrm{~mm}$.

As médias observadas para cada acesso demonstraram que os tetraplóides V 8611, Mr s/n e PI 347238 (tabela 1) apresentaram maiores valores médios para o tamanho dos estômatos, $0,038 \mathrm{~mm}$ e $0,036 \mathrm{~mm}$. A média decresceu para os acessos GL 460-76 (0,031mm) e V $12820(0,033 \mathrm{~mm})$, ambos tetraplóides. O acesso diplóide PI 364878 teve média igual ao tetraplóide V 12820, não diferindo estatisticamente. A utilização desse critério para diferenciar diplóides e tetraplóides de Hemarthria altissima, não foi eficaz. SCHIFINO (1985) mediu o tamanho dos estômatos e relatou que houve superposição das médias e das medidas individuais entre os dois níveis de ploidia em Trifolium riograndense. Conseqüentemente, este critério não pode ser utilizado para selecionar com certeza os indivíduos $4 \mathrm{X}$ de Trifolium riograndense. Ao contrário, LACERDA et al. (1994) mediram o tamanho dos estômatos em Paspalum redondense, obtendo resultados que demonstraram eficácia para definir nível de ploidia entre os indivíduos desta espécie.

\section{CONCLUSÕES}

O diâmetro dos grãos de pólen Médias seguidas de letras iguais não diferem entre si em nível de 5\% pelo teste de TuKey.
Tabela 2 - Diâmetro médio dos grãos de pólen e tamanho médio dos estômatos em acessos de Hemarthria altissima.

$\begin{array}{llllll}\text { Tetraplóides } & \mathrm{Mr} / \mathrm{sn} & 200 & 0,034 \mathrm{~b} & 100 & 0,036 \mathrm{~b} \\ \text { brasileiros } & \mathrm{V} 8611 & 200 & 0,036 \mathrm{a} & 100 & 0,038 \mathrm{a} \\ 2 \mathrm{n}=4 \mathrm{x}=36 & \mathrm{~V} 12820 & 200 & 0,035 \mathrm{a} & 100 & 0,033 \mathrm{c}\end{array}$

pode ser utilizado para caracterizar os diferentes níveis de ploidia (diplóides e 


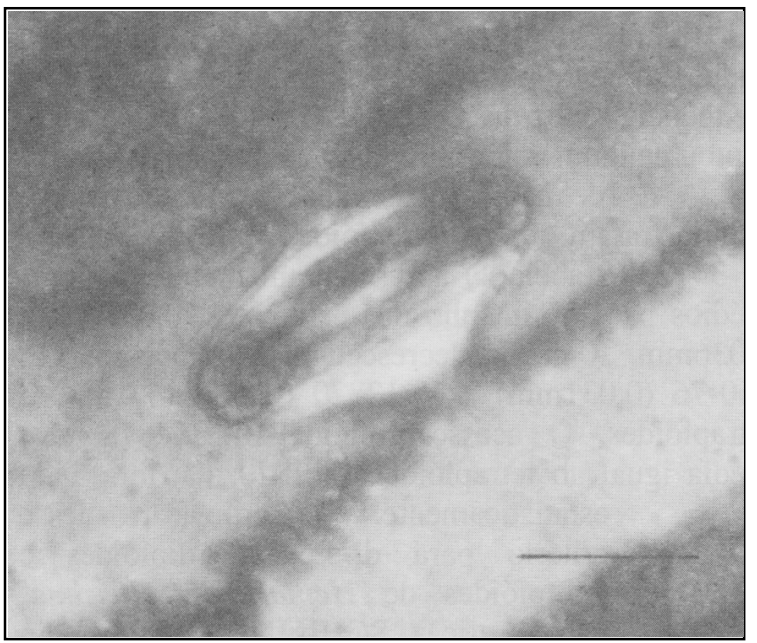

Figura 3 - Estômato de Hemarthria altissima, PI 364878 $(2 \mathrm{n}=2 \mathrm{x}=18)$. Escala $=10 \mu \mathrm{m}$.

tetraplóides) em Hemarthria altissima. O tamanho dos estômatos não pode ser considerado como um critério seguro de caracterização, nesta espécie.

\section{AGRADECIMENTOS}

Agradecemos ao Professor José Henrique Souza da Silva, do Departamento de Zootecnia da Universidade Federal de Santa Maria, pelo auxílio na análise estatística dos dados deste trabalho.

\section{REFERÊNCIAS BIBLIOGRÁFICAS}

ALLEM, A., VALLS, J.F. Recursos forrageiros nativos do Pantanal Mato-Grossense. Brasília-DF: EMBRAPA-DF, EMBRAPA-CENARGEN, 1987. 339 p., Documento 8.

BURKART, A. Flora Ilustrada de Entre Rios, parte II. Buenos

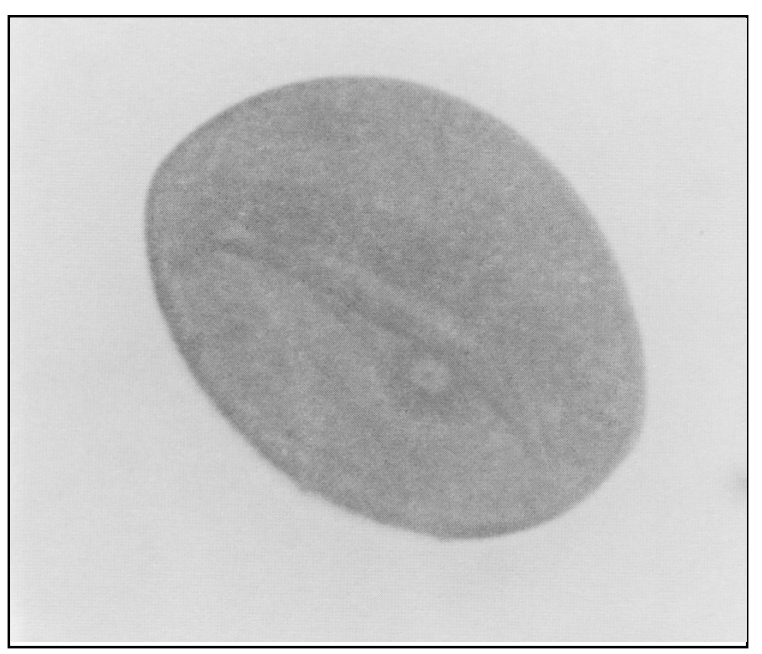

Figura 2 - Grãos de pólen Hemarthria altissima, tetraplóide $(2 n=4 x=36)$. Aumento: $2250 x$.

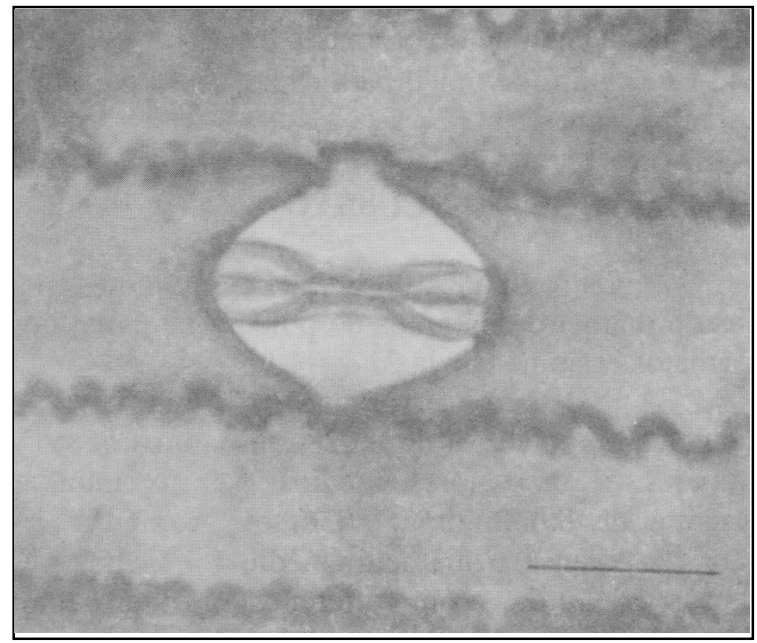

Figura 4 - Estômato de Hemarthria altissima, GL 460-76 $(2 \mathrm{n}=4 \mathrm{x}=36)$. Escala $=10 \mu \mathrm{m}$.

Aires: INTA, 1969. p. 458-459.

KILLINGER, G.B. Limpograss (Hemarthria altissima (Poir.) Stapf et. C. E. Hubb. ) a promising forage and beverage grass for the South. Agronomy Abstracts, Madison, v. 63, p. 56, 1971.

LACERDA, R.C.A., VALLS, J.F.M., POZZOBON, M.T Caracterização morfológica e citogenética de acessos de germoplasma de Paspalum redondense Swallen (gr. Caespitosa). Brasília: CENARGEN/EMBRAPA, 1994. (datil.).

NICOLINI, M. P. Estudo histotaxonômico do gênero Panicum no Rio Grande do Sul. Santa Maria, RS. 1967. 174 p. Tese (Doutorado) - Faculdade de Farmácia e Bioquímica, Universidade Federal de Santa Maria, 1967.

POSTIGLIONI, S. R. Hemarthria altissima, uma forrageira para a região dos Campos Gerais do Paraná. Londrina: IAPAR, 1983. Circular, 36.

SCHANK, S.C., KLOCK, M.A., MOORE, J.E. Laboratory evaluation of quality in subtropical grasses: II Genetic variation among Hemarthrias "in vitro" digestion and stem morphology. Agronomy Journal, Madison, v. 65, p. 256-258, 1973 .

SCHIFINO, M.T. Estudos citogenéticos em Trifolium riograndense Burkart, T. polymorfum Poir. e T. repens L.: Indução de poliploidia, número cromossômico, cariótipo, comportamento meiótico. Porto Alegre - RS. 255p. Tese (Doutorado em Ciências) - Curso de Pós-graduação em Genética, Universidade Federal do Rio Grande do Sul, 1985.

SMITH, L.B., WASSHAUSEN, D.C. Chave para os gêneros das gramíneas brasileiras. Bradea, Rio de Janeiro, v. 3, p. 1-35, 1981.

VALLS, J.F.M. Principais gramíneas forrageiras nativas das diferentes regiões do Brasil. In: III SIMPÓSIO SOBRE PRODUÇÃO ANIMAL. Campo Grande, 1986. Anais... Campo Grande: Fundação Cargil, 1986. p. 75-86. 130p.

WILMS, H.J., CARMICHAEL, J.W., SCHANK, S.C. Cytological and morphological investigations on the grass Hemarthria altissima (Poir) Stapf et C. E. Hubb. Crop Science, Madison, v. 10, p. 309-312, 1970. 